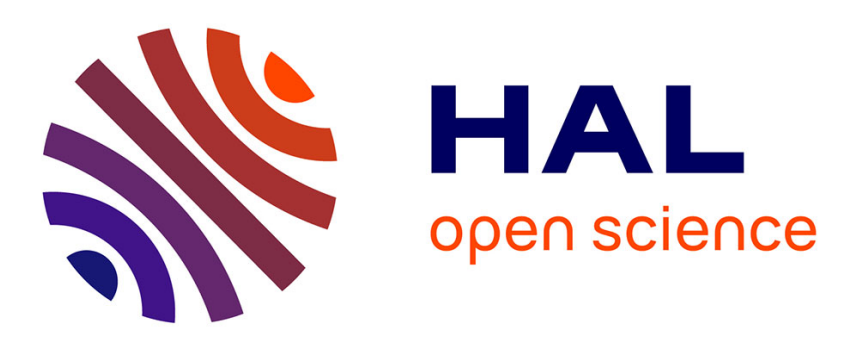

\title{
Strategies for optimizing the mechanical strengths of raw earth-based mortars
}

\author{
A. Perrot, Damien Rangeard, F. Menasria, S. Guiheneuf
}

\section{To cite this version:}

A. Perrot, Damien Rangeard, F. Menasria, S. Guiheneuf. Strategies for optimizing the mechanical strengths of raw earth-based mortars. Construction and Building Materials, 2018, 167, pp.496-504. 10.1016/j.conbuildmat.2018.02.055 . hal-01807170

\section{HAL Id: hal-01807170 \\ https://hal-univ-rennes1.archives-ouvertes.fr/hal-01807170}

Submitted on 28 Aug 2018

HAL is a multi-disciplinary open access archive for the deposit and dissemination of scientific research documents, whether they are published or not. The documents may come from teaching and research institutions in France or abroad, or from public or private research centers.
L'archive ouverte pluridisciplinaire HAL, est destinée au dépôt et à la diffusion de documents scientifiques de niveau recherche, publiés ou non, émanant des établissements d'enseignement et de recherche français ou étrangers, des laboratoires publics ou privés. 


\section{Strategies for optimizing the mechanical strengths of}

\section{2 raw earth-based mortars}

3

4

5

6 behavior of earth mortars notably under a compressive load.

\author{
A. Perrot ${ }^{1, *}$, D. Rangeard ${ }^{2}$, F. Menasria ${ }^{2}$, S. Guihéneuf ${ }^{2}$
} *arnaud.perrot@univ-ubs.fr

2 INSA Rennes, EA 3913, LGCGM, F- 35000 Rennes, France

* corresponding author

1 Univ. Bretagne Sud, FRE CNRS 3744, IRDL, F-56100 Lorient, France

Abstract Earth-based mortars are commonly reinforced with bio-based materials such as straw or biopolymers. The aim of this work is to identify reinforcements that are able to improve the mechanical strengths and the ductility of an earth-based matrix. We have also attempted to describe the mechanisms of reinforcement involved in such materials. Firstly, a kaolinite-based clay soil was mixed with sand to achieve earth-based mortars with the highest density at the dry state. For this material (kaolinite-based mortar), we have shown that, at the same water content, the compressive strength at the dry state only depends on the dry density of the sample whatever the forming process. Various quantities of fibers, fabrics and alginate were then used to reinforce the studied mortars (a kaolinite based mortar and a natural soil containing swelling clay sieved at $4 \mathrm{~mm}$ ). We found that these reinforcements significantly increase the compressive strength of all tested samples containing kaolinite. A comparison between the two materials helps us to understand the reinforcement mechanisms for various fibers; it also demonstrates that natural fibers and woven fabrics enhance the mechanical 
Keywords: Earth-based materials, flax fibers, woven flax fabric, alginate.

26

\section{Introduction}

Earthen construction has recently regained much attention in the building industry due to its low environmental impact and recyclability [1-4]. The development of earthen construction is still limited because of the time required for the material to harden and by the difficulty to achieve a mix-design that allows for both fast casting and sufficient strength in the dry state. In order to address both problems and to improve mix-design of earth-based mortars, a recent trend has been to apply scientific knowledge and expertise, developed by the concrete industry, to earthen construction[4-8].

One of the options adopted from concrete technology is the optimization of the granular skeleton [4] which increases the dry density of earth mortars and thus its mechanical strength. Another option is to use a coagulant, a biopolymer or a hydraulic binder in order to shorten the material's hardening stage [9-18]. Another solution, emanating from concrete mix design, is to improve the earth mortar's workability to enable the possibility of making an extrudable, flowable and even castable earth mortar [4-6]. The objective of using a dispersant is to deflocculate the micro-sized clay-based structures in order to reduce the interaction force between clay particles. Deflocculation can be obtained by using a dispersant which acts just like a superplasticizer on cement particles in concrete $[6,19-23]$. This option is also expected to lead to a reduction of the material porosity and therefore improve material strength and durability [4].

In this study, the first option was used to obtain a material with a continuous particle size distribution, leading to a dense matrix, by adding fine and coarse sand. Two materials were used, a commercial kaolin powder mixed with sand and an earth-based material which is 
known to be suitable for cob construction. The earth-based mortar can be either compacted or

51 cast by adding a dispersant hexametaphosphate (HMP) thus making the mortar flowable. In this study, HMP was used as a dispersant because it has been shown to be more efficient than cement superplasticizer for reducing the yield stress of kaolin mortar [6]. Finally, alginate was also added in order to obtain a rapid strength gain of the earth. The effects of alginate and dispersant on the compressive strength of the materials were also tested.

Various water to dry material mass ratios were tested to find an optimal value that gave the highest mortar densities for different forming process. An assessment of the material behavior was also made to see if it was influenced by the forming process.

Following the powder mix-design, reinforcement strategies were tested using dispersed flax fibers and woven fabrics made of flax fibers. These different reinforcement strategies were tested within the framework of this study. Following a description of the materials and methods, the following evaluations were carried out on the earth-based mortars; the effects of particle size distribution optimization; the influence of processing and bio-based reinforcements (alginate or flax individual fibers or woven fabrics) on ductility, compressive and flexural strength of earth-based mortars. Finally, the combined effects of the different reinforcement types were assessed.

\section{Materials and methods}

\section{II.1 Materials}

The kaolin clay used was provided by Imerys and came from the "Kaolins de Bretagne" quarry at Ploemeur, France. The kaolin clay had a specific gravity of 2.65 and a specific surface area of $10 \mathrm{~m}^{2} / \mathrm{g}$ (data provided by the supplier). The largest clay grain size was approximately $10 \mu \mathrm{m}$ and the mean kaolin grain size approximately $4 \mu \mathrm{m}$. The particle size 
was measured using a laser particle size analyzer and is set out in figure 1. Before measurement, the sample was dispersed in a suspension of distilled water with a deflocculant agent (sodium hexametaphosphate Na-HMP) at 2,500 rpm stirrer speed. The suspension was placed in the measurement cell, and an ultrasonic stimulation was carried out for 30 seconds before measurement.

The mortar used in the tests consisted of a mixture of kaolin clay powder, sand and water. The clay was mixed with two different sands: fine sand, with grain size ranging from 63 to $200 \mu \mathrm{m}$, and coarser sand with grain size ranging from 0 to $4 \mathrm{~mm}$. The grain size distributions of the sands are also plotted in figure 1. The fine sand particle size distribution was obtained by laser diffraction and the coarse sand distribution was obtained by sieving.

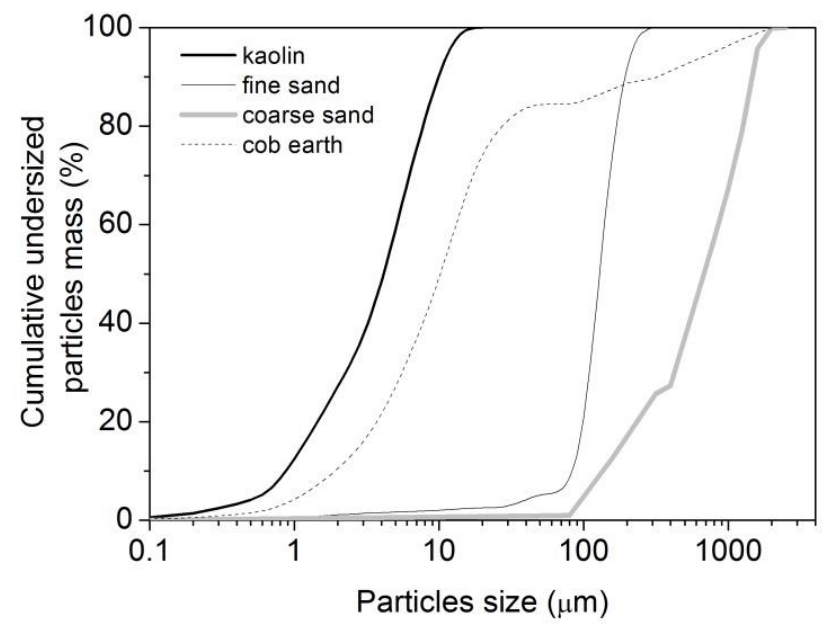

Fig. 1: Particle size distribution of the powders and Saint-Sulpice-La-Forêt soil (cob earth) In order to optimize the particle size distribution (PSD) of the kaolin-based mix, the method proposed by Dreux and Gorisse [24] to determine the optimized ratio of sand to gravel was used to obtain the densest aggregates packing. As three different particle types were used, a two steps computation was performed. Firstly, the kaolin clay and the fine sand PSD were used to obtain the optimized PSD of the clay/fine sand mix (binary mix). The optimized PSD 
of the binary mix was then used together with the PSD of the coarse sand to find the optimized PSD of the ternary mix of clay/fine sand/coarse sand.

The final PSD of the ternary mix of dry particles was optimized using Dreux and Gorisse method [24] which is plotted in figure 2. This composition allows for the best mechanical strength with this ternary mix (see next section and in [25]). The mix was composed by mass (and volume, as all particles have almost the same density) as follows 17\% kaolin, 23\% fine sand and $60 \%$ coarse sand. A plateau in the PSD can be seen between 10 and $60 \mu \mathrm{m}$, as neither the kaolin nor the sand have those particle sizes.

The second material tested was a cob earth from Saint-Sulpice-La-Forêt (Ille et Vilaine, France). It was a fine soil with $70 \%$ of particles finer than $10 \mu \mathrm{m}$ (the PSD is plotted on figure 1 and was obtained in the same way as the kaolin PSD). The soil particles were a mix of quartz, and various types of clay: kaolinite, illite and smectite; this being determined by $\mathrm{XRD}$ analysis before and after thermolysis at $550^{\circ} \mathrm{C}$. The Plasticity Index of this soil was 21 with a liquid limit of $48 \%$ and a plastic limit of $27 \%$.

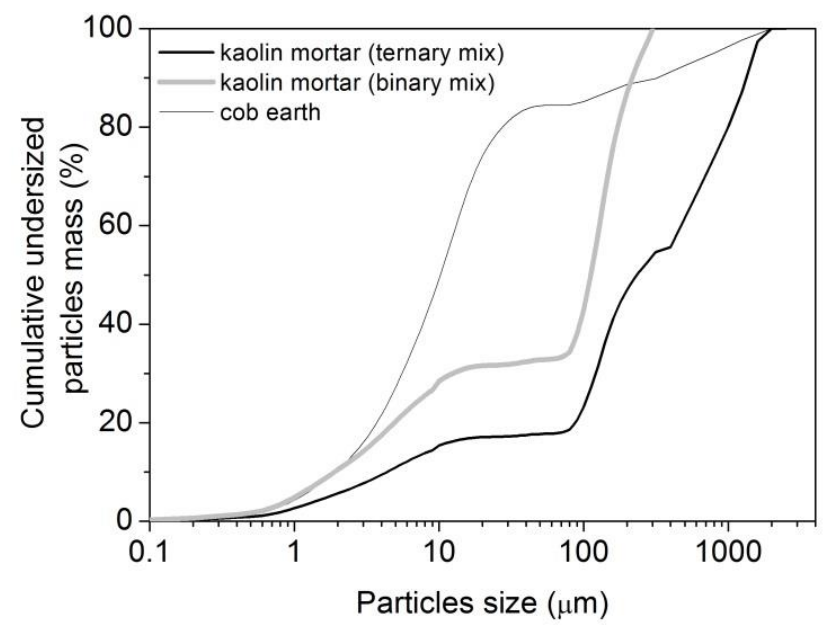


113 The alginate used in the study was a white powder of alginic salt Cimalgin HS3® provided by

114 Cimaprem (Redon, France). It is designed to make high strength gel for arts and molding 115 applications. Dosage rates used ranged from $1 \%$ to $5 \%$ of particles smaller than $10 \mu \mathrm{m}$. The

116 HS3 product is mostly composed of alginate salt with an "on demand" calcium release agent

117 that allows the monitoring of the duration of the alginate gel network creation. Alginate can

118 form a cross-linked isotropic insoluble gel when a soluble form of alginate nucleates with

119 divalent metal cations, like $\mathrm{Ca}^{2+}$, which can be found in earth-based materials. Chains of

120 alginate make junctions by intercalating divalent cations creating a sort of egg-box connection

121 [26]. In order to aid the dispersion of alginate within the earth material, the HS3 powder is

122 firstly mixed with an equal mass of water.

123 Hexametaphosphate (HMP) was used in this study as a dispersant to make a mortar flowable.

124 For the kaolin mortar, a dosage of $0.25 \%$ of the kaolin clay content was tested, this being

125 based on previously obtained results on the effect of dispersant on the rheological behavior of

126 clay pastes [6]. For the cob earth from Saint-Sulpice-La-Forêt, the mass ratio of HMP was

$1270.3 \%$ of the dry material. The choice of this dosage was made using the same methodology as

128 that used for the kaolin mortar in [6].

130 The dispersed flax fibers (Marylin variety) used in this study was supplied by the CTLN®

131 Company (Le Neubourg, France). The fibers, shown on Figure 3, were scutched, carded and

132 cut into $4 \mathrm{~mm}$ lengths. These flax fibers were the same as those used in the study by

133 Bourmaud et al. [27]. The volume fraction of fibers ranging from 1 to $4 \%$ was used in the

134 present study. The woven fabric of flax fibers was isotropic with a mesh size of $4 \mathrm{~mm}$. The

135 mass per unit area of the fabric textile was $500 \mathrm{~g} / \mathrm{m}^{2}$.

136 Dispersed flax fibers and woven fabric of flax fibers were tested as reinforcements (Figure 3). 


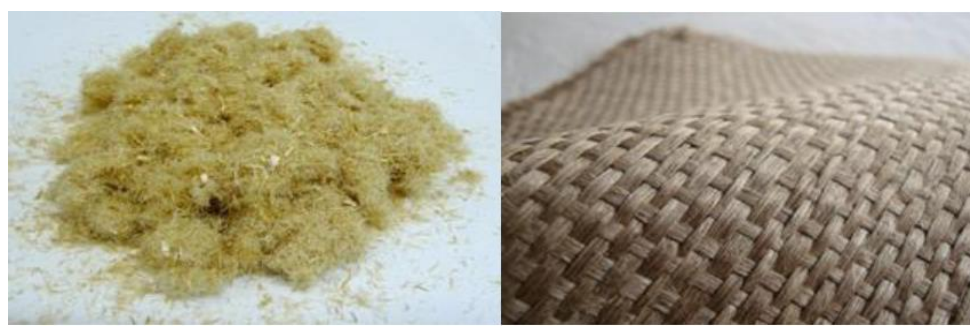

138 Fig. 3: Dispersed flax fibers and woven flax fiber fabric.

II.2 Methods

141 The earth samples were prepared using high capacity Hobart mixer. Dry powder was firstly

142 introduced into the bowl. When using fiber reinforced material, dry fibers were mixed with

143 the dry powder by hand until a homogeneous material with well dispersed fibers was

144 obtained. Water was then added, the quantity being that necessary to attain the targeted water

145 content. The mixing procedure consisted of a 4 minutes low velocity mixing stage, followed

146 by a high velocity mixing stage of 5 minutes. Between these two stages, the bowl was scraped

147 in order to ensure that no unmixed material remained adhered to the bowl. After mixing, the

148 material was placed in a closed container for 24 hours to allow homogenization.

149 The alginate solution was prepared just before casting and/or compaction and was mixed with

150 the wet earth using a mortar hand mixer for 4 minutes.

151 Cylindrical samples of $50 \mathrm{~mm}$ diameter and height were compacted using static compression

152 with a $200 \mathrm{kN}$ loading frame at a maximum vertical stress of $45 \mathrm{MPa}$. To compare the effect

153 of the compaction technique a Proctor-type dynamic compaction was used to make $150 \mathrm{~mm}$

154 diameter and height samples. Samples were compacted in CBR mold, in five layers with 56

155 blows of CBR ram for each layer. For cast samples, cement mortar 40x40x160 $\mathrm{mm}^{3}$ moulds 156 were used.

157 Because all the compressive tests were carried out with samples of an aspect ratio of one

158 (sample height to diameter for cylindrical samples or sample side length for prismatic 159 samples), it is considered that mechanical measurements can be compared even if their 
160 geometries are different. The comparison between results obtained with those different sizes

161 and shapes of samples was acceptable as it has been shown that at a same aspect ratio, the

162 strength variation due to shape variation is lower than 5\% [28]].

163 Samples were then conserved in a $50^{\circ} \mathrm{C}$ temperature controlled store until weight

164 stabilization. Such a temperature allows a relatively fast drying and ensures that only free

165 water leaves the sample. After this curing step, once the sample weight was stabilized, it was

166 considered that the samples were dry. The compressive strength of the sample was then

167 measured using a $50 \mathrm{kN}$ loading frame. The test was carried out at a constant velocity of

$1681 \mathrm{~mm} / \mathrm{min}$ which is in agreement the French national standard recommendation for soils

169 testing XP CEN ISO TS 17892-7 (the test duration ranging between 2 and 15 minutes,

170 maximum strain rate of $2 \%$ per minute).

171

172 III Effect of particle size distribution and processing

173

174 III.1 Effect of particle size distribution

175 The particle size distribution of the mortar was designed to obtain the highest density once

176 placed. Concepts from concrete mix-design were used in order to obtain the densest packing.

177 It is also important to note that the binder content (here the kaolin clay) must be kept higher

178 than a critical value that will ensure sufficient cohesion within the sample.

179 It is interesting to note that using the Dreux and Gorisse method, the amount of binder is

180 equal to $17 \%$ of the total mass of powder. This value can be considered as lower bound when

181 dealing with clay content commonly found in earth construction.

182 In order to emphasize that this step of PSD optimization is paramount, clay samples, of binary

183 mixes (fine sand + kaolin) and of ternary mixes (coarse sand + fine sand + kaolin), were

184 prepared with different water contents ranging from $5 \%$ to $10 \%$, these were then compacted 
185 in a CBR mould in 5 layers using 56 blows per layer. The samples were weighted after

186 drying and mechanically tested to measure their compressive strength.

187 Figure 4 shows the compressive strength as a function of the dry density of the samples.

188 Results show that the widening of a continuous particle size distribution increases dry density

189 of the samples and therefore their compressive strength, as commonly observed $[29,30]$.

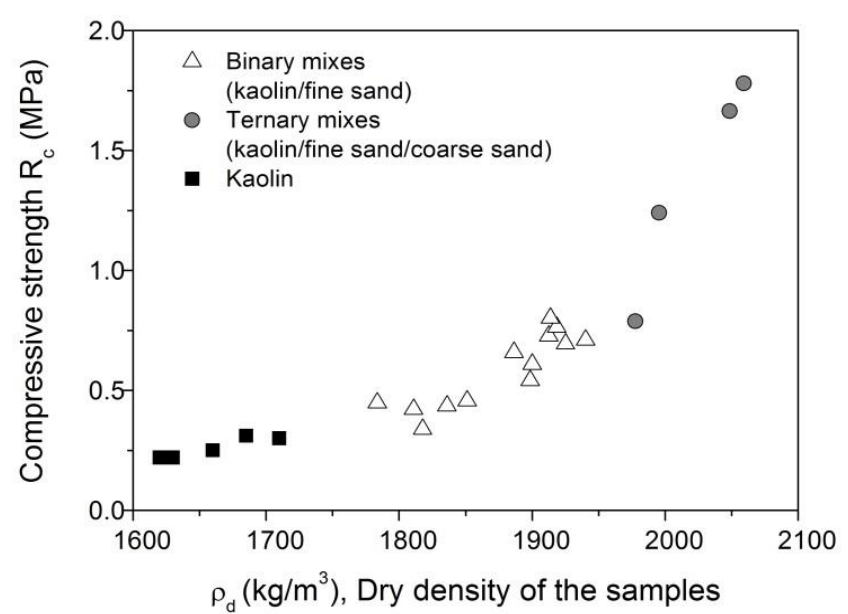

191 Fig. 4: Compressive strength as a function of dry density for kaolin, binary mix (fine sand+kaolin) and ternary mix (coarse sand+fine sand+kaolin)

193

194 In the following sections of this paper, only the ternary mix was used.

195 It is interesting to note that we attempted to add a limestone filler with a particle size

196 distribution ranging from 10 to $63 \mu \mathrm{m}$ (ie in the range of the size not present in the PSD

197 shown in figure 3). Using this fourth material, optimized PSD provides kaolin volume fraction

198 of around $10 \%$ that was not sufficient to obtain a cohesive product after casting or

199 compaction. This result is in agreement with that which can be found in the literature 200 suggesting that a minimal content of clay is needed to make earth-based materials for 201 construction [31-33].

202 Another crucial point is that for the cob earth the results were opposite: Using the same 203 methodology, we obtained a mix of $40 \%$ cob earth, $29 \%$ fine sand and $31 \%$ coarse sand. Such 
204 mixes result in an increase in the dry density of the mixture, initial values ranging between 2051780 and $1850 \mathrm{~kg} / \mathrm{m}^{3}$ which increased to values ranging from 1950 to $2050 \mathrm{~kg} / \mathrm{m}^{3}$. However, 206 this densification of the dry matrix leads to a decrease of the compressive strength from above $2078 \mathrm{MPa}$ to values of the order of $2.5 \mathrm{MPa}$. Therefore, for the cob earth which contains clay that 208 can induce relatively high compressive strength (8 MPa for an earth-based materials), the 209 strength of the material appears to be directly linked to the clay content (Figure 5).

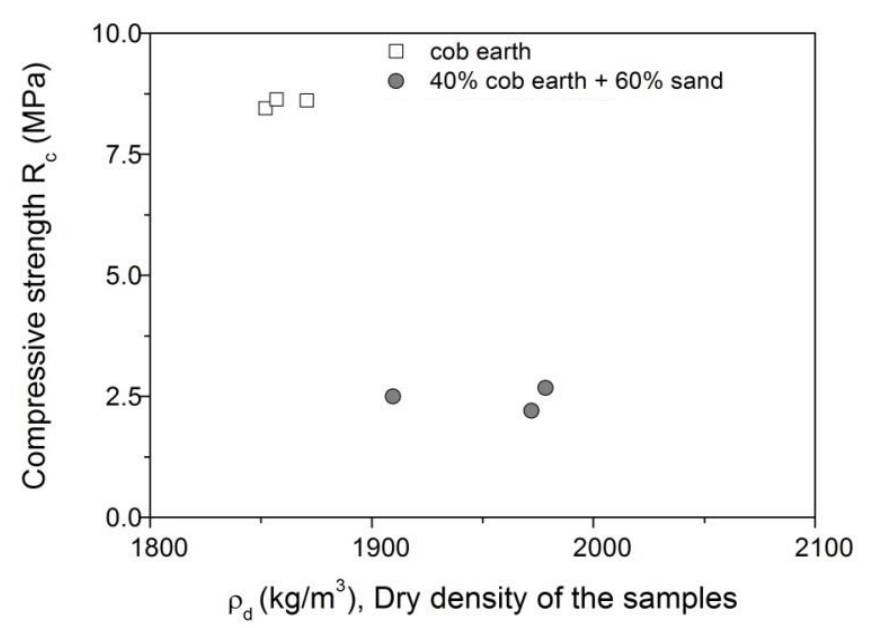

211 Fig. 5: Compressive strength as a function of dry density for cob earth with and without 212 additional sand.

214 The effect of the densification of earth-based material strengthening directly depends on the 215 type of clays contained in the earth. With pure kaolinite, which has a low compressive 216 strength (around $500 \mathrm{kPa}$ ), a densification of the matrix with sand, leads to a significant 217 increase in strength. As opposed to this, the high strength cob earth content directly governs 218 the strength of the samples.

III.2 Effect of processing and dispersant

221 This part of the study is focused on the kaolin mortar and it is to be noted that the same kind 222 of trend has been observed for the cob earth. 
223 Figure 6 shows the evolution of the dry density of cast and compacted samples with respect to 224 initial water content. The curves show that the optimal water content for obtaining the densest 225 material depends on the forming process. Dynamic compaction required the smallest water 226 content, in this case $5.5 \%$ of the dry particles mass, whereas casting required more water $227(14 \%)$ to obtain the densest material, and was therefore the material with the best mechanical 228 properties. Between these two forming process, static compaction (maximum load of $25 \mathrm{MPa}$ ) 229 showed a maximum dry density for an initial water content of $10 \%$. These results indicate 230 that the rheology (or the consistency) of the wet material must be optimized with regard to the 231 forming process.

232 It is also interesting to note that the maximum density obtained for each type of tested 233 forming process was in the same range (between 2050 and $2080 \mathrm{~kg} / \mathrm{m}^{3}$ ). Using higher energy 234 of compaction would result in a higher density as proposed by [34].

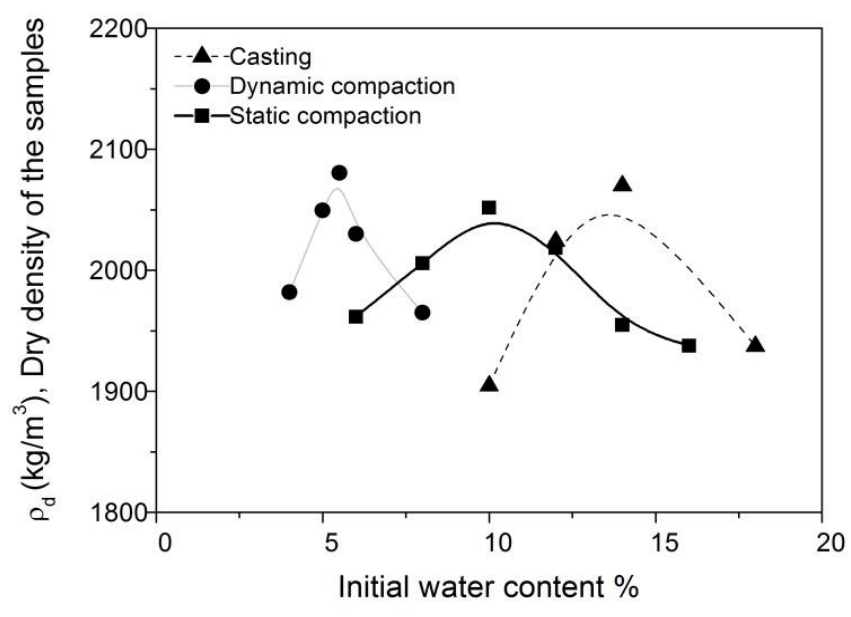

236 Fig. 6: Influence of the initial water content (water added during mixing) on the dry density of 237 the samples for the three forming process. .

239 For the optimized water content for the static compaction at $25 \mathrm{MPa}$, it was observed that an 240 increase of the vertical stress from 25 to $45 \mathrm{MPa}$ led to an increase of the dry density from 
2412060 to $2100 \mathrm{~kg} / \mathrm{m} 3$. Thus, for the static compaction process, the final dry density was also

242 depended on the loading.

243 The curve of the compressive strength versus the dry density is shown in figure 7 . All the

244 results are grouped around two lines, the first relate to the mixes containing HMP and the 245 second to the mixes without HMP. For a same density, mixes with HMP present a higher 246 mechanical strength. This increase could be due to a better dispersion of the clay particles, as 247 shown by $[4,6]$, that would improve the mechanical properties of the dry materials.

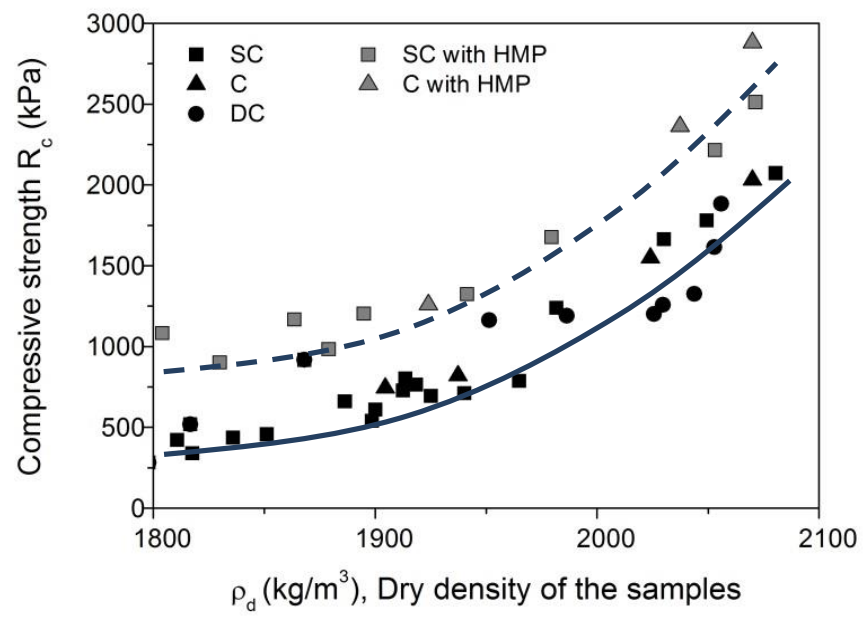

249 Fig. 7: Evolution of the compressive strength of the sample after drying versus the dry density

250 for the different forming processes and with and without HMP addition.

252 It can be seen that the compressive strengths of the dry samples increases from $0.5 \mathrm{MPa}$ to 2 $253 \mathrm{MPa}$, for mixes without HMP, and from 0.8 MPa to 2.8 MPa, for mixes containing HMP, 254 when the dry density increases from 1800 to $2080 \mathrm{~kg} / \mathrm{m}^{3}$. This trend can be explained by a 255 better distribution of the clay particles with HMP. HMP reduces interaction forces between 256 clay particles in a fresh state and allows for an increase of the distance at the contact point 257 between particles and a decrease of the average pore size [6]. In this case, the effect of HMP 258 would be the same as the one of superplasticizer within cement paste [23]. 
259 It is also worth noting that the forming process does not influence the mechanical strength.

260 Two samples made with different forming processes, both having the same dry density, will 261 have the same compressive strength.

\section{Fibers and fabrics reinforcement}

IV.1 Woven fabric

The woven flax fabric was placed between layers of earth-based material, compacted or cast in the surface perpendicular to the direction of loading during compressive strength measurements. All test samples had an aspect ratio of 1 . The number of woven fabric sheets in a sample, tested in this study, ranged from 1 to 4 . The sample containing one woven fabric present two layers of material with a dimensionless height of 0.5 (ratio of the layer height to the total sample height). In a general form, the height of cast and compacted earth-based materials is equal to $1 /(n+1)$ where $n$ is the number of woven fabric sheets. It is to be noted that in order to obtain layers of equal height a target mass of earth-based material for a layer

274 was computed assuming the density obtained with no woven fabric.

275 In Figure 8, the dimensionless compressive strengths of samples with woven fabrics (i.e. the ratio of the compressive strength to the compressive strength of the samples without fabric) are plotted versus the dimensionless height of earth-based material layer. It appears that the reinforcement effect of woven fabric did not depend on the forming process.

279 For the tested materials (kaolin mortar and cob earth), it appears that there is a relationship 280 between the reinforcement effect of the woven fabric and the height of an elemental layer of 281 earth-based material between woven fabric sheets. These results are in agreement with results 282 previously obtained in the work of P'kla $[35,36]$ and more generally with works on the reinforcement of soils by geotextiles and geomembranes [37, 38]. 


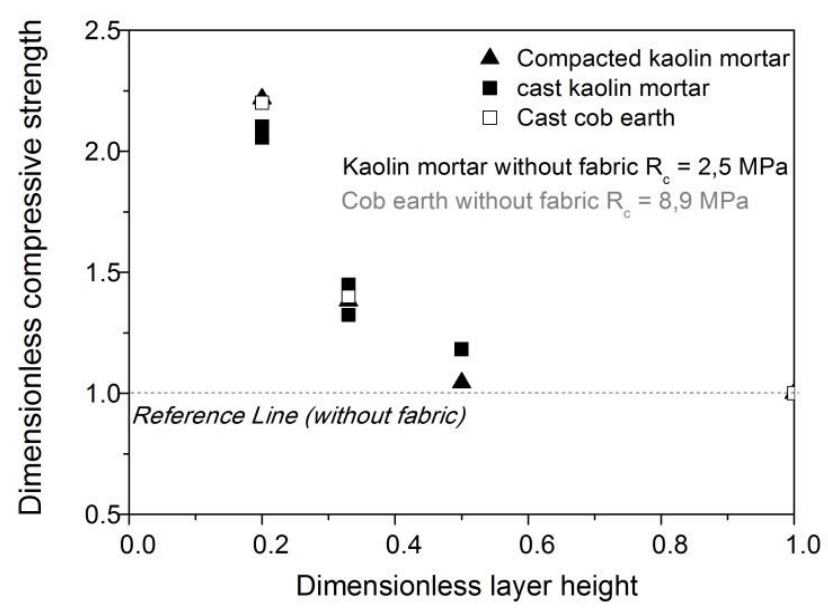

285 Fig. 8: Dimensionless compressive strength of fabric reinforced samples versus the 286 dimensionless height of layers of earth-based materials.

288 Figure 9 shows a fabric reinforced sample before and after a compressive strength test. 289 Fracture occurred at the fabric interface which indicates shear at this interface. Moreover, the 290 vertical fractures do not always cross the fabric interface from one layer to another thus 291 indicating that the sample behaves as a vertical assembly of partially independent layers of 292 earth-based materials. As these elemental layers have a lower aspect ratio, the compressive 293 strength of the sample increases as the height of the elemental layer decreases.

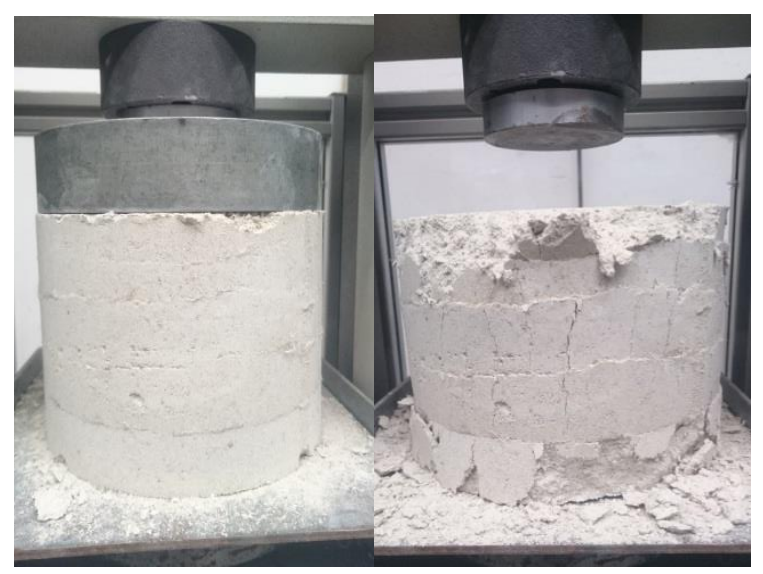

295 Fig. 9: Observation of the dynamically compacted samples with 4 woven fabric sheets before and after the compressive strength test. 
To conclude, it is interesting to note that the maximum compressive strengths of the sample

299 was obtained with 4 woven fabric sheets (the maximum number of fabric sheets tested); the

300 compressive strength were 4.5 MPa for cast samples, 4.35 MPa for compacted samples for the

301 kaolin mortar and 17.6 MPa for the cast cob earth. Another benefit of woven fabric is that the

302 large increase in compressive strength is accompanied by a decrease in dry density of the

303 sample; dry densities are reduced from 2080 to $2050 \mathrm{~kg} / \mathrm{m}^{3}$ in the case of compacted samples

304 and from 2070 to $1930 \mathrm{~kg} / \mathrm{m}^{3}$ in the case of cast samples).

305

\subsection{Flax fibers}

307 Flax fibers were mixed with the dry powder before the addition of water. Volume fractions of

308 fiber ranging from 1 to $4 \%$ were tested in this study. Figure 10 shows the evolution of 309 dimensionless compressive strength of the sample versus the fiber volume fraction added to 310 the earth-based materials. It can be seen that in the case of kaolin mortar, the increase of the 311 compressive strength does not depend on the forming process but is directly linked to the fiber 312 content; the higher the fiber content, the higher the compressive strength. This observation is 313 generally true for the tested materials provided that the fibers do not cause workability issues 314 as is commonly observed in fiber-reinforced concrete rheology $[39,40]$.

315 For the statically compacted samples with $4 \%$ volume content of flax fiber, the compressive 316 strength was 5.6 MPa, which is more than twice the compressive strength obtained without 317 fibers. Moreover, it is important to note that the dry density of this sample decreased from 3182070 to $1920 \mathrm{~kg} / \mathrm{m}^{3}$.

319 For kaolin mortar, the increase in compressive strength with fiber content is quite surprising because it is not observed with cement-stabilized clay or concrete [14]. However, in this case,

321 the tested mineral matrix has a lower mechanical strength and the mechanical contribution 
resulting from the friction/shear at the fiber/matrix interface becomes a non-negligible factor

323 in compressive strength.

324 This latter supposition is supported by the fact that in the case of cob earth, which has a higher 325 compressive strength, the contribution of fibers to the compressive strength is less than that 326 seen in the case of kaolin mortar, see Figure 10.

327 This observation indicates that the reinforcement contribution of fiber to the overall 328 compressive strength depends on the relative strength of the fiber interface with respect to the 329 strength of the matrix; that is to say the lower the matrix strength the higher the fiber 330 reinforcement's contribution to strength.

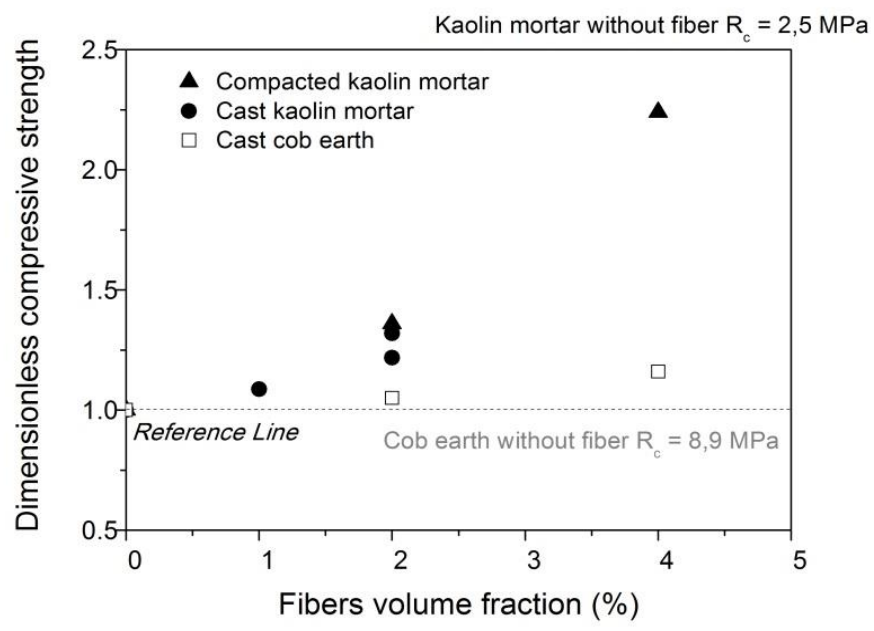

332 Fig. 10: Dimensionless compressive strength of fiber reinforced samples versus the volume 333 fraction of fibers contained in earth-based materials.

\section{Effect of alginate biopolymer}

337 Once the samples were dry compressive strengths of the samples are measured once the 338 samples were dry to provide a reference state for further testing. Figure 11 shows the evolution of the compressive strength with respect to sample dry density for kaolin mortar 
samples made with different amounts of alginate; Figure 12 shows a similar evolution for the

341 cob earth from Saint-Sulpice-La-Forêt.

342 For kaolin mortar, the addition of alginate at a $1 \%$ dosage did not change the mechanical 343 strength of the sample. In this case, the amount of alginate may not be sufficient to build a gel 344 network able to reinforce the material. However, for higher dosage, the compressive strength 345 of the sample increased with the alginate dosage. For a 3\% dosage, and a dry density of 2050 $346 \mathrm{~kg} / \mathrm{m}^{3}$, the addition of alginate more than doubled the compressive strength (from $2.25 \mathrm{MPa}$ to $3475.9 \mathrm{MPa}$ ). At a dosage of 5\%, the compressive strength reached its maximum value of 7.1 $348 \mathrm{MPa}$. It would be of interest to test higher dosages in further work to verify if increased 349 dosage result in a higher compressive strength and what is the critical dosage for which the 350 compressive strength reaches a plateau.

For the cob earth from Saint-Sulpice-La-Forêt, the addition of alginate did not change the compressive strength of the samples. Figure 12 shows that the evolution of sample compressive strength with respect to dry density was not influenced by the addition of alginate in the range of dosage tested (from 0 to $4 \%$ ). It can be assumed that structure of the material without alginate is stronger (or at least of equal strength) than the alginate gel network. Therefore, it is noted that the addition of alginate did not modify the mechanical strength of the samples as it did not reinforce the soils particles network that has stronger interactions; this maybe due to the presence of swelling clays like smectite at a dry state (high 360 suction effect).

361 By comparing the effect of alginate addition on the compressive strength of both materials, it can be concluded that the ability of alginate to strengthen an earth-based materials depends on 363 its dosage and on the mineralogy of the clay particles in the soil. Figure 13 summarized the 364 effect of alginate on both tested materials with respect to its dosage. 


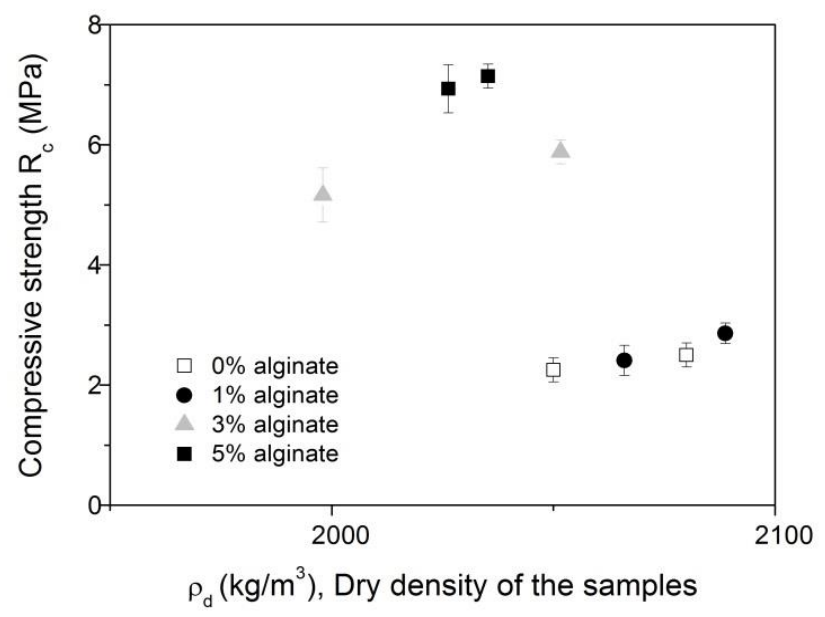

367 Fig. 11: Compressive strengths versus dry density curves of cast kaolin mortar samples with 368 alginate content (mass fraction of the kaolin powder) ranging from 0 to $5 \%$.

For kaolin earth-based material, the addition of a sufficient amount of alginate was able to 371 strengthen the material (up to three times the compressive strength of the sample without any 372 alginate).

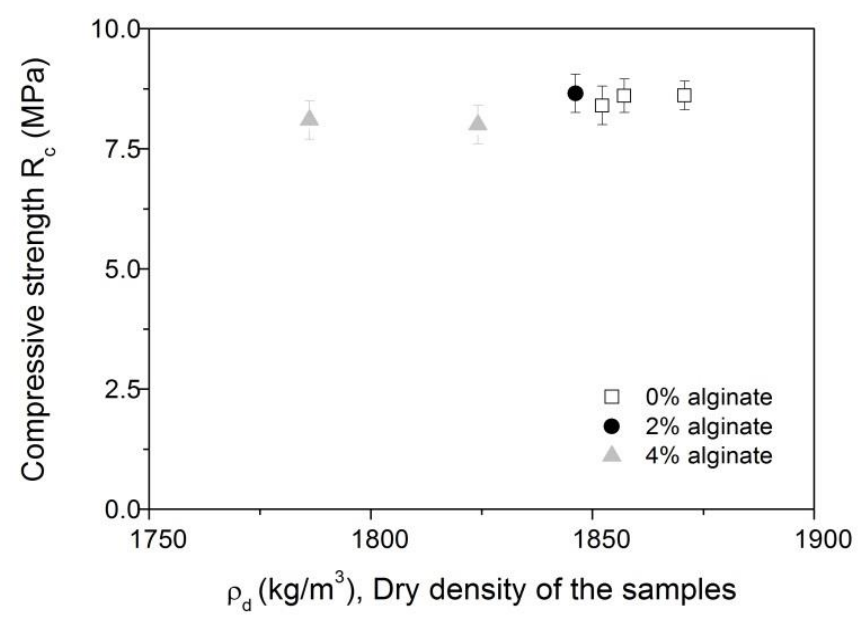

374 Fig. 12: Compressive strengths versus dry density curves of cast cob earth (Saint-Sulpice-La-

375 Forêt) mortar samples with alginate content (mass fraction of the soil) ranging from 0 to $4 \%$.

On the other hand, in the case of the soil from Saint-Sulpice-La-Forêt that contains swelling 378 clay (smectite), alginate does not increase the compressive strength of the material, even at 

network.

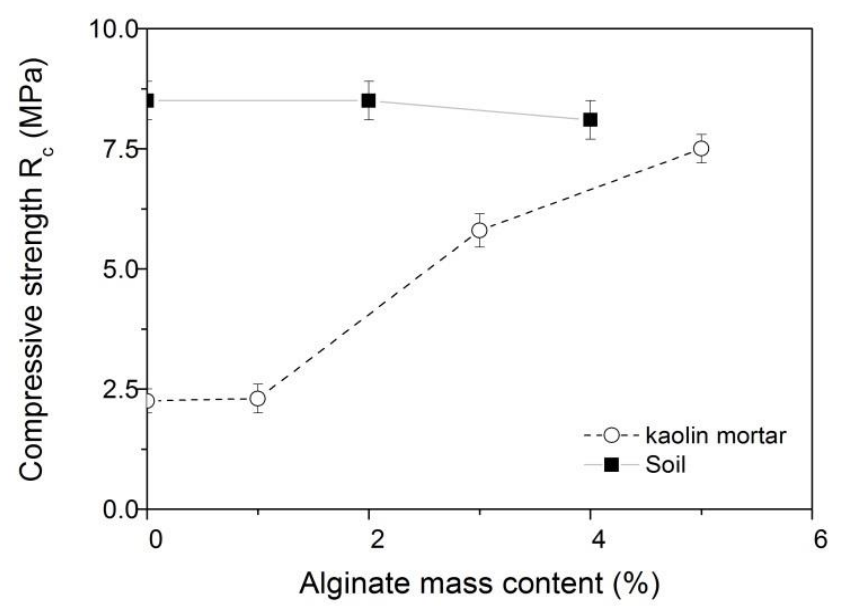

Fig. 13: Evolution of compressive strength of tested materials with alginate dosage at a fixed dry density (extrapolated value at $2050 \mathrm{~kg} / \mathrm{m}^{3}$ for the kaolin mortar and $1850 \mathrm{~kg} / \mathrm{m}^{3}$ for the cob earth from Saint-Sulpice-La-Forêt).

\section{Coupled reinforcement effects}

This section reports on a study made of the effect of coupled reinforcement strategies used to strengthen the material. This work focused on kaolin mortar because only the fabric sheets have been shown able to increase the compressive strength of cob earth whereas for the kaolin paste, all types of reinforcements have strengthened the material.

394 Figure 14 shows the evolution of the compressive strength of the kaolin mortar sample with 395 respect to dry density. Firstly, it can be seen that the addition of flax fibers induces a decrease in the sample density. This decrease can be attributed to two phenomena: a workability decrease due to the fibers (leading to higher void content) and to the low density of the fibers. 
398 Secondly, the mechanical strength of the samples only increases with the addition of fibers for 399 an alginate dosage of $1 \%$. It appears that for higher dosage, fibers do not increase the 400 compressive strength of the samples because the cohesion of the material is higher than the 401 interfacial strength between fiber and mineral matrix as shown in Menasria et al.[25]. For 402 dosages of 3 and $5 \%$ of alginate, the addition of fibers appears to have no effect as the 403 mechanical strengths of samples with and without fibers lie along the same strength density 404 curve for each fiber dosage (Figure 14).

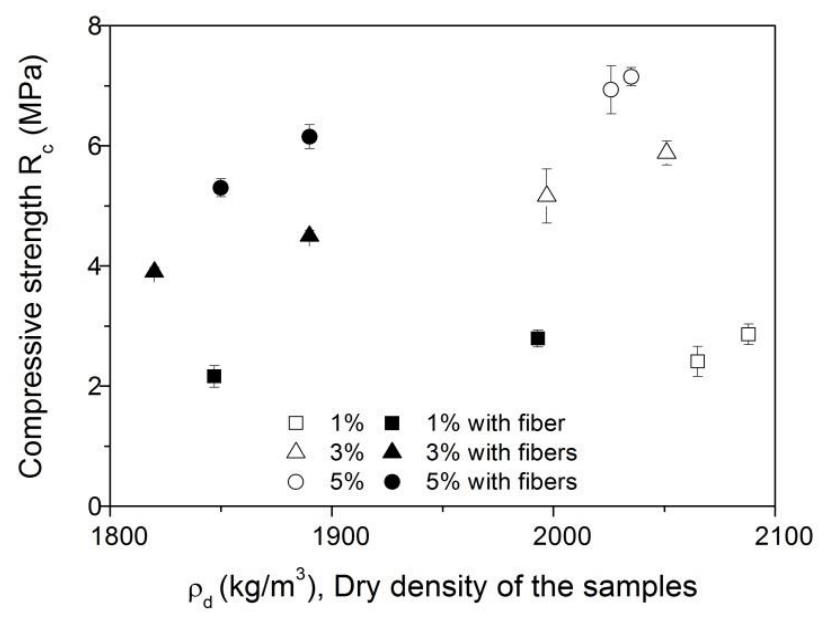

Fig. 14: Evolution of sample compressive strength of kaolin mortar with dry density for different dosages or alginate (1,3 and 5\%) with and without flax fibers. The compressive strength of the kaolin without fiber is 2 MPa for a dry density of $2080 \mathrm{~kg} / \mathrm{m}^{3}$

One beneficial aspect brought about by the fibers is the increased ductility of the material.

411 Figure 15 shows force displacement curves obtained during the compressive strength 412 measurements with and without fibers for alginate dosages of 3 and 5\%. If the curves for 413 samples with and without fibers are compared, it can be see that the elastic parts of the curve 414 before the peak are close, thus indicating that fiber addition does not significantly influence 415 the elastic modulus. The load peak is higher for samples without fibers, as confirmed by 416 Figure 8, however, after the load peak; the load decrease is much slower for samples with 
417 fibers. Such type of behavior indicates an increase in the ductility of the sample; this is a very

418 interesting material property for earth construction in a seismic area, for example.

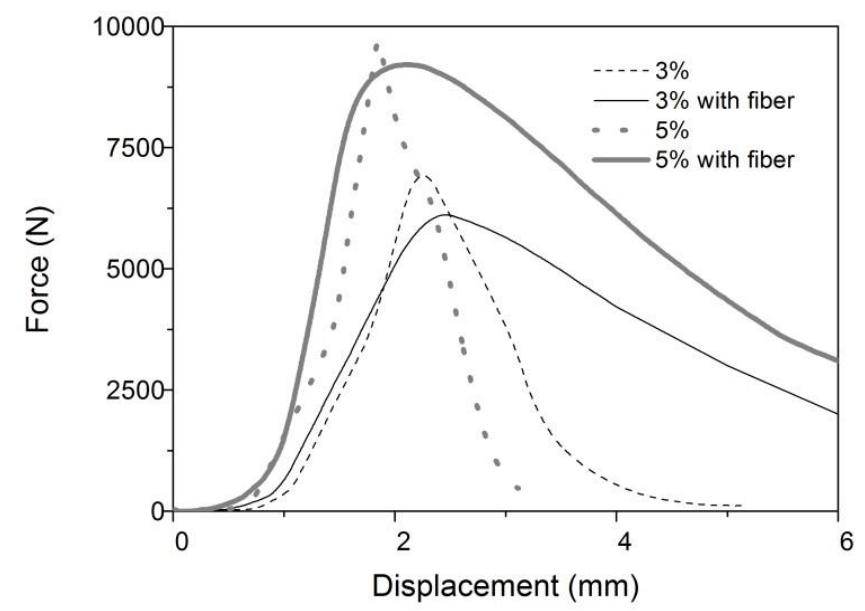

420 Fig. 15: Force versus displacement curves obtained during the compressive strength

421 measurements on kaolin mortar with and without fiber for alginate dosages of 3 and $5 \%$.

Figure 16 shows the evolution of flexural strength of the kaolin mortar samples with respect to dry density, for different dosages of alginate (1, 3 and $5 \%$ ) with and without fibers. The results are close to those obtained for compressive strength. Once again, the beneficial effect of fibers on the strength is obtained only for the lowest alginate dosage for which the mineral matrix is the weakest. For higher dosages of alginate, the influence of fibers is not so obvious but the flexural strength remains constant even if the dry density decreases with the addition of fibers. This type of behavior can be attributed to the level of tensile strength of the flax fibers that can act in tension when embedded in a low-strength material. 


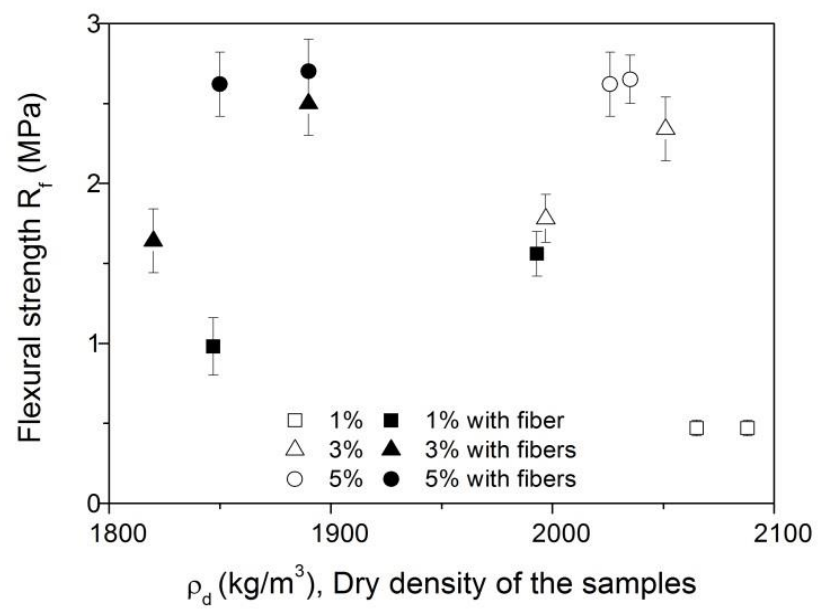

432 Fig. 16: Evolution of compressive strength of samples of kaolin mortar with dry density for

433 different dosages or alginate (1,3 and 5\%) with and without flax fibers.

Figure 17 shows the force displacement curves measured during the flexural strength tests.

436 We can see that samples without fiber exhibit a brittle behavior with a sudden failure obtained 437 after the load peak whereas the samples with fibers shows a post-peak behavior with a smooth 438 decrease of the load due to the continuous failure of the interfaces between fibers and matrix $439 \quad[14]$

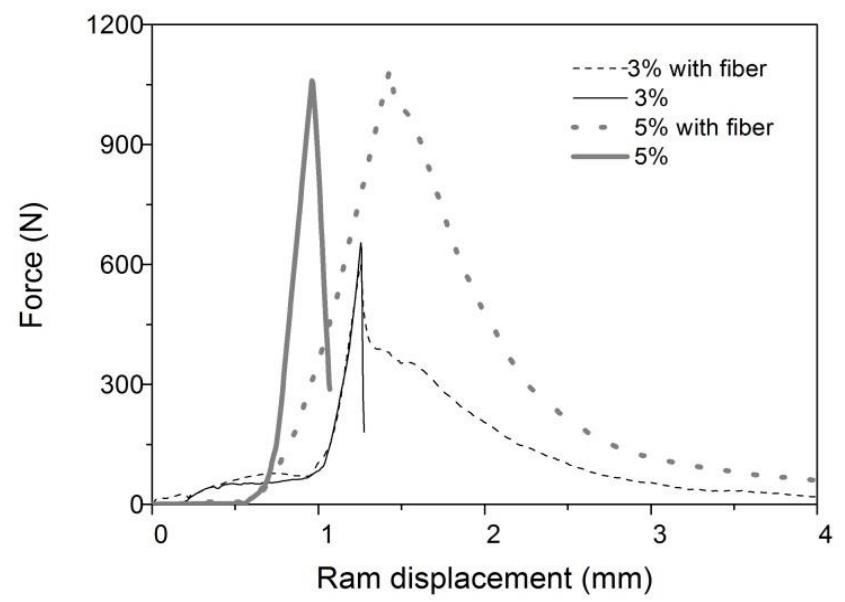

441 Fig. 17: Force versus displacement curved obtained during the flexural strength measurements on kaolin mortar with and without fiber for alginate dosages of 3 and 5\%. 
444 VI.1 Alginate, flax and fabric: Toward earth-based high performance composites.

445 In order to complete this study of reinforcement of earth-based materials, a study was carried 446 out on the effect of combining alginate, fibers and woven fabrics on the compressive strength 447 of the kaolin mortar. A kaolin mortar with a water content of $12 \%$ containing HMP and an 448 alginate dosage of $3 \%$ and with a volume fraction of flax fiber of $4 \%$ was cast in $44940 \times 40 \times 160 \mathrm{~mm}^{3}$ mould in five layers separated by the tested woven fabric. After the drying 450 stage, the sample was tested in compression. The compressive stress vs. the deformation 451 curve (Figure 18) shows that the compressive strength of the material was quite high 17.5 $452 \mathrm{MPa}$. However, the elastic modulus remained only at a value of $110 \mathrm{MPa}$, which is quite low 453 in comparison with the elastic modulus of concrete at the same level of compressive strength.

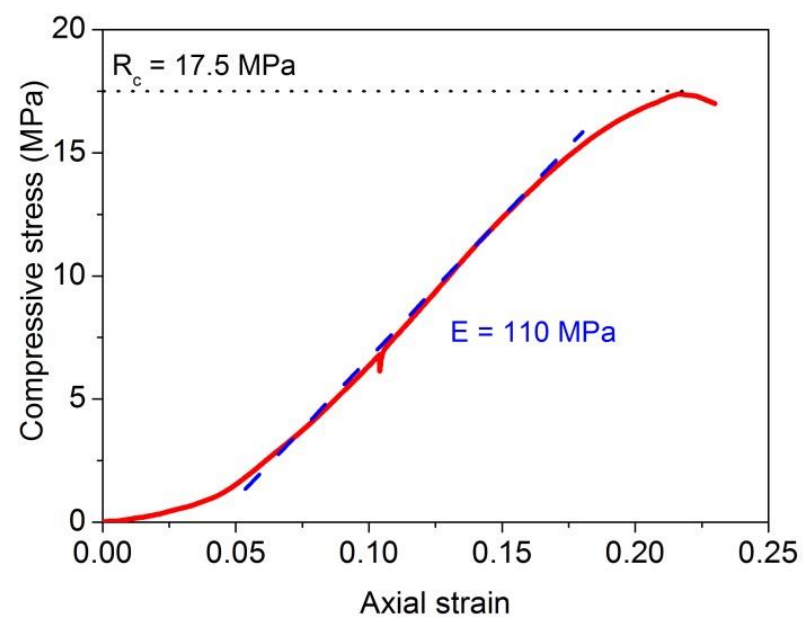

Fig. 18: Stress versus deformation curves obtained during the compressive strength measurements on $40 \times 40 \times 40$ cubic samples of kaolin mortar with $4 \%$ fibers, $0.25 \%$ HMP, alginate dosage of $3 \%$ and 4 woven fabrics.

459 This shows that the reinforcement strategies and their combination help to delay the failure of 460 the samples by giving some bridging between clay particles provided by alginate or fibers. 461 However, it clearly appears that these reinforcements do not affect the elastic modulus, which 
462 is always of the order of kaolin without reinforcement (150 MPa for the same material 463 without fibers and alginate).

\section{Conclusions}

467 In this article, several strategies for optimizing the mechanical resistance of the earth material 468 were tested. It appears that the effect of the reinforcement depends on the nature of the soil 469 tested and of the mineralogical nature of the clay.

470 Firstly, we have been able to assess the influence of dry density and dispersion of clay

471 particles (by using HMP and granular optimization) for a cob earth and a kaolin mortar. In the

472 case of kaolin mortar, which had the highest dry density, optimization of the compressive 473 strength was possible whereas in the case of cob earth containing other types of clay 474 (smectite), it was observed that the compressive strength is governed by the clay content and 475 could not be optimized.

476 An interesting result shows that the compressive strengths of the dry samples do not depend 477 on the forming process but only on the dry density of the material.

478 The benefit provided by alginate and textile reinforcements depended on the nature of the 479 earth. While their actions are highly beneficial for kaolin-based soils, it is almost negligible 480 for materials containing swelling clay that initially have a high initial resistance (>8 $\mathrm{MPa})$ in 481 the dry state.

482 Finally, by combining all types of reinforcement strategies, it was possible to make a material 483 with high compressive strength (18 MPa) and high deformability. 
Acknowledgement: The authors would like to thank the Ecomaterre project led and managed

486

487

488

489

490

491

492

493

494

495

496

497

498

499

500

501

502

503

504

505

506

507

508

509

510

511

512

513

514

515

516

517

518

519

by the IAUR (Institut d'Aménagement et d'Urbanisme de Rennes) and the ACROTERRE association for its action of structuring regional research on earth construction.

\section{References}

1. Azeredo G, Morel J-C, Lamarque C-H (2008) Applicability of rheometers to characterizing earth mortar behavior. Part I: experimental device and validation. Mater Struct 41:1465-1472 . doi: 10.1617/s11527-007-9343-9

2. Bui Q-B, Morel J-C, Hans S, Meunier N (2009) Compression behaviour of nonindustrial materials in civil engineering by three scale experiments: the case of rammed earth. Mater Struct 42:1101-1116 . doi: 10.1617/s11527-008-9446-y

3. Aubert JE, Maillard P, Morel JC, Al Rafii M (2015) Towards a simple compressive strength test for earth bricks? Mater Struct 1-14 . doi: 10.1617/s11527-015-0601-y

4. Moevus M, Jorand Y, Olagnon C, et al (2015) Earthen construction: an increase of the mechanical strength by optimizing the dispersion of the binder phase. Mater Struct 1-14 . doi: $10.1617 / \mathrm{s} 11527-015-0595-5$

5. Gnanli L, Ouellet-Plamandon C, Brumaud C, Habert G (2014) Development of a SelfCompacted Clay based Concrete, rheological, mechanical and environmental investigations. Barcelona, Spain

6. Perrot A, Rangeard D, Levigneur A (2016) Linking rheological and geotechnical properties of kaolinite materials for earthen construction. Mater Struct 49:4647-4655 . doi: 10.1617/s11527-016-0813-9

7. Landrou G, Brumaud C, Habert G (2017) Clay particles as binder for earth buildings materials: a fresh look into rheology of dense clay suspensions. In: EPJ Web of Conferences. EDP Sciences, p 13010

8. Ouellet-Plamondon CM, Habert G (2016) Self-Compacted Clay based Concrete (SCCC): proof-of-concept. J Clean Prod 117:160-168 . doi: 10.1016/j.jclepro.2015.12.048

9. Landrou G, Brumaud C, Winnefeld F, et al (2016) Lime as an Anti-Plasticizer for SelfCompacting Clay Concrete. Materials 9:330

10. Walker P, Stace T (1997) Properties of some cement stabilised compressed earth blocks and mortars. Mater Struct 30:545-551 . doi: 10.1007/BF02486398

11. Venkatarama Reddy BV, Prasanna Kumar P (2011) Cement stabilised rammed earth. Part A: compaction characteristics and physical properties of compacted cement stabilised soils. Mater Struct 44:681-693 . doi: 10.1617/s11527-010-9658-9 
12. Venkatarama Reddy BV, Prasanna Kumar P (2011) Cement stabilised rammed earth. Part B: compressive strength and stress-strain characteristics. Mater Struct 44:695-707 . doi: $10.1617 / \mathrm{s} 11527-010-9659-8$

13. Khelifi H, Perrot A, Lecompte T, Ausias G (2013) Design of clay/cement mixtures for extruded building products. Mater Struct 46:999-1010 . doi: 10.1617/s11527-012-99494

14. Khelifi H, Lecompte T, Perrot A, Ausias G (2015) Mechanical enhancement of cementstabilized soil by flax fibre reinforcement and extrusion processing. Mater Struct 1-14

15. Tripura D, Singh K (2014) Behavior of cement-stabilized rammed earth circular column under axial loading. Mater Struct 1-12 . doi: 10.1617/s11527-014-0503-4

16. Miccoli L, Oliveira D, Silva R, et al (2015) Static behaviour of rammed earth: experimental testing and finite element modelling. Mater Struct 48:3443-3456 . doi: 10.1617/s11527-014-0411-7

17. Van Damme H, Houben H (2017) Earth concrete. Stabilization revisited. Cem Concr Res. doi: 10.1016/j.cemconres.2017.02.035

18. Pinel A, Jorand Y, Olagnon C, et al (2017) Towards poured earth construction mimicking cement solidification: demonstration of feasibility via a biosourced polymer. Mater Struct 50:224 . doi: 10.1617/s11527-017-1092-9

19. Roussel N, Lemaitre A, Flatt RJ, Coussot P (2010) Steady state flow of cement suspensions: A micromechanical state of the art. Cem Concr Res 40:77-84 . doi: 10.1016/j.cemconres.2009.08.026

20. Kjeldsen AM, Flatt RJ, Bergström L (2006) Relating the molecular structure of combtype superplasticizers to the compression rheology of $\mathrm{MgO}$ suspensions. Cem Concr Res 36:1231-1239 . doi: 10.1016/j.cemconres.2006.03.019

21. Flatt RJ (2004) Dispersion forces in cement suspensions. Cem Concr Res 34:399-408 . doi: 10.1016/j.cemconres.2003.08.019

22. Perrot A, Lecompte T, Khelifi H, et al (2012) Yield stress and bleeding of fresh cement pastes. Cem Concr Res 42:937-944 . doi:

http://dx.doi.org/10.1016/j.cemconres.2012.03.015

23. Zingg A, Holzer L, Kaech A, et al (2008) The microstructure of dispersed and nondispersed fresh cement pastes - New insight by cryo-microscopy. Cem Concr Res 38:522-529 . doi: http://dx.doi.org/10.1016/j.cemconres.2007.11.007

24. Dreux G, Festa J (1998) Nouveau guide du béton et de ses constituants. Eyrolles

25. Menasria F, Perrot A, Rangeard D, Le Duigou A (2017) Mechanical enhancement of casted and compacted earth-based materials by sand, flax fiber and woven fabric of flax. Clermont-Ferrand, France 
26. Funami T, Fang Y, Noda S, et al (2009) Rheological properties of sodium alginate in an aqueous system during gelation in relation to supermolecular structures and $\mathrm{Ca} 2+$ binding. Food Hydrocoll 23:1746-1755

27. Bourmaud A, Morvan C, Bouali A, et al (2013) Relationships between micro-fibrillar angle, mechanical properties and biochemical composition of flax fibers. Ind Crops Prod 44:343-351

28. Yi S-T, Yang E-I, Choi J-C (2006) Effect of specimen sizes, specimen shapes, and placement directions on compressive strength of concrete. Nucl Eng Des 236:115-127

29. Morel J-C, Pkla A, Walker P (2007) Compressive strength testing of compressed earth blocks. Constr Build Mater 21:303-309

30. Bruno AW, Gallipoli D, Perlot-Bascoules C, et al (2015) Briques de terre crue: procédure de compactage haute pression et influence sur les propriétés mécaniques. In: Rencontres Universitaires de Génie Civil

31. Maniatidis V, Walker P (2003) A review of rammed earth construction. Innov Proj "Developing Rammed Earth UK Housing" Nat Build Technol Group Dep Archit Civ Eng Univ Bath

32. Delgado MCJ, Guerrero IC (2007) The selection of soils for unstabilised earth building: A normative review. Constr Build Mater 21:237-251

33. McHenry PG (1984) Adobe and rammed earth buildings: design and construction. University of Arizona Press

34. Bruno AW, Gallipoli D, Perlot C, Mendes J (2017) Mechanical behaviour of hypercompacted earth for building construction. Mater Struct 50:160 . doi: $10.1617 / \mathrm{s} 11527-017-1027-5$

35. Pkla A, Mesbah A, Rigassi V, Morel JC (2003) Comparaison de méthodes d'essais de mesures des caractéristiques mécaniques des mortiers de terre. Mater Struct 36:108-117 . doi: 10.1007/BF02479524

36. P'Kla A (2002) Caractérisation en compression simple des blocs de terre comprimée (BTC): application aux maçonneries" BTC-Mortier de terre." Villeurbanne, INSA

37. Guido VA, Chang DK, Sweeney MA (1986) Comparison of geogrid and geotextile reinforced earth slabs. Can Geotech J 23:435-440

38. Lawrence CA (2014) 8 - High performance textiles for geotechnical engineering: geotextiles and related materials. In: High Performance Textiles and their Applications. Woodhead Publishing, pp 256-350

39. Perrot A, Lecompte T, Estellé P, Amziane S (2013) Structural build-up of rigid fiber reinforced cement-based materials. Mater Struct 46:1561-1568

40. Martinie L, Rossi P, Roussel N (2010) Rheology of fiber reinforced cementitious materials: classification and prediction. Cem Concr Res 40:226-234 
593

594

595 